\title{
Legal Frameworks for Early Childhood Governance in the Philippines
}

\author{
Marilyn F. Manuel \\ Euberto B. Gregorio \\ Early Childhood Care and Development Council \\ Philippines
}

\begin{abstract}
The Early Childhood Care and Development (ECCD) Act of 2000 is the national ECCD policy framework of the Philippines. A basic element of this framework is shared governance. This model exemplifies governance mechanisms at national, provincial, city/municipal and barangay levels to support delivery of integrated ECCD services. A decade of implementing this policy framework provides an excellent starting point and a rich context for looking at the current state of governance of ECCD in the country. The salient features of the ECCD Act and other related policies serve as a backdrop for the discussion of the progress and challenges of ECCD governance. This article concludes with three interrelated policy agenda that would strengthen the country's governance of early childhood.
\end{abstract}

Key words: early childhood care and development policy, governance

\section{Introduction}

ECCD programs and services in the Philippines are not new. Health, nutrition, early education and psychosocial care, parenting education and other social services for children ages 0 to 6 and their families have been the government's concerns instituted in its various line departments. What is new and promising is the promulgation of a national ECCD policy framework that provides, among others, the institutional structures at all levels to implement the national ECCD policy. The ECCD law is a very

Correspondence concerning this article should be addressed to Marilyn F. Manuel, Deputy Director and Euberto B. Gregorio, Planning Officer for Early Childhood Care and Development Council, 5th Floor PDAP Building 407 Sen. Gil Puyat Avenue Bel-Air Village, Makati City 1200 Philippines. Electronic mail may be sent to m_manuel47@ymail.com or eubertog@yahoo.com significant policy step to provide the mechanisms to integrate and harmonize multi-sectoral ECCD initiatives. This paper presents an overview of the current state of ECCD governance particularly at the national level.

\section{The Country Context}

The 2007 population census reported an enumeration of 88.57 million Filipinos (NSO, 2008).

About 46 percent are children below 18 years old; the 0 to 6 years of age represent about 18 percent of the total population. In 2000, the population of children 0 to 6 years old was 13.5 million; by 2010 the number is projected to increase to 17.2 million or 3.6 million more children (0-6) than in 2000 (NSO). The magnitude and increase in this age group indicates a high dependency ratio and would entail significant 
additional resources needed to provide basic needs such as food, health care, education.

On the macro level, high population growth is tied to poverty. The poverty incidence in the country increased from 30 percent in 2003 to 32.9 percent in 2006 (NEDA \& UNDP, 2010).

The challenges facing Filipino children today relate to poor health and nutrition, limited early education and or lack of appropriate psycho-social care and stimulation, inadequate protection - and more recently, climate change. These core threats to the optimum well-being of young children have implications in guaranteeing child rights to survival, development and protection. The problems are closely linked and indicate an urgent need for an intensive and integrated effort to ensure the optimum development of children (0 to 6).

A major poverty intervention program in the country to guarantee child rights and ensure child well-being and development is ECCD. The implementation of ECCD in the country is governed by Republic Act No. $8980^{1}$ or the ECCD Act of 2000. Before the enactment of the ECCD Act, various statutes were promulgated to cater to the sectoral concerns of children - health, nutrition, education, social protection/social welfare.

\section{Legal Frameworks for Governance of Early Childhood Care and Development}

Two major laws are cited because of its implications on the status of ECCD governance in the country. These are: (1) The Child and Youth Welfare Code of 1974 which codified the rights and duties of children, the duties and responsibilities of parents, the community and various stakeholders in promoting the welfare of Filipino children and youth (0 to 21) and created the Council for the Welfare of Children (CWC) as the national coordinating body on children and youth concerns; and (2) The Local Government Code of 1991 that provided for a more accountable local government structure instituted through a system of decentralization and mandated the devolution of basic services to the local government units (particularly health and social welfare). A brief description of the ECCD Act follows.

\section{Salient Features of the ECCD Act}

The law includes a policy statement to promote the rights of children to survival, development, and social protection and to support parents in their roles as primary caregivers and as their children's first teachers. It spells out the vision for an improved quality of life for children 0 to 6 and their families. It also mandates the establishment of multi-sectoral coordinating mechanisms to ensure sustained collaboration at national and local levels. Moreover, the law incorporates funding commitments to finance the implementation of the national ECCD policy.

Establishment of the National ECCD System: The law provides that the State shall establish and institutionalize a national system for ECCD that is: (1) comprehensive, a holistic approach that addresses the development of the whole child - physical, social, emotional, mental and spiritual); (2) integrative, a system that promotes the delivery of complementary health, nutrition, early childhood education, social protection and other social services to children 0 to 6 and their families; (3) sustainable, the system is collectively owned and supported by the local government, the community and families; and (4) involves multi-sectoral and interagency collaboration at the national and local levels among various stakeholders.

The ECCD system is best understood as the comprehensive, integrative and sustainable policies, programs and structures designed to ensure the well being, optimum growth and development of children 0 to 6. Policies need to be translated into ECCD programs/projects/activities $(\mathrm{P} / \mathrm{P} / \mathrm{A})$, which in turn requires mechanisms/structures to transform this $\mathrm{P} / \mathrm{P} / \mathrm{A}$ into action to benefit the 0 to 6 and their 


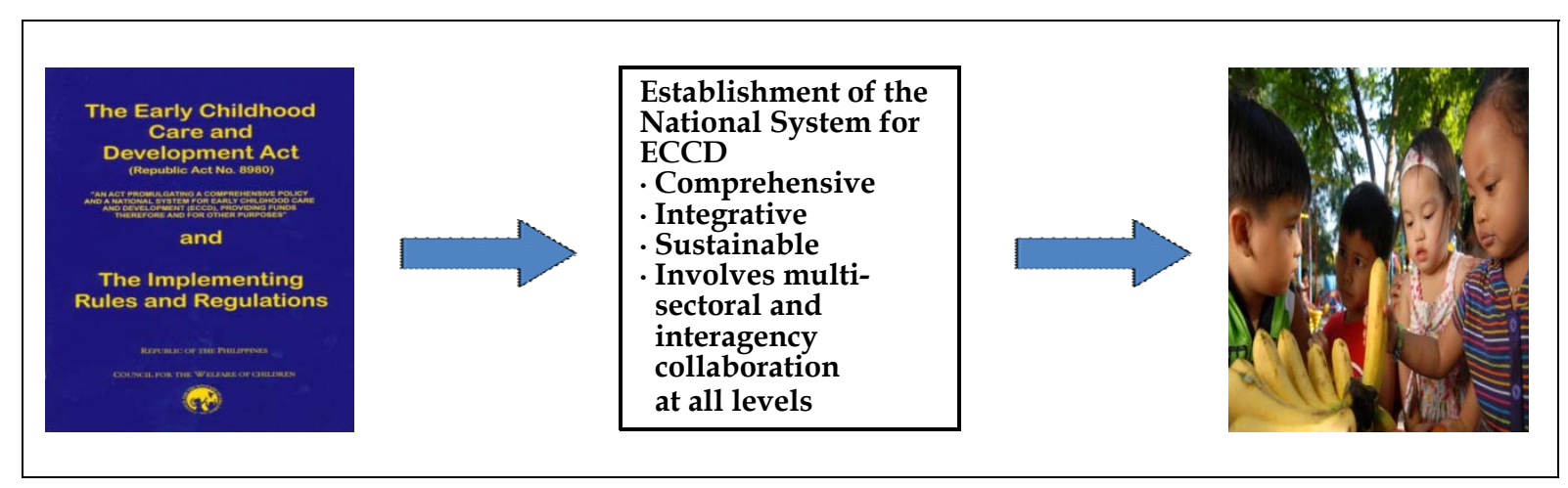

Figure 1. Establishment of the National ECCD System

families.

The ECCD System Program Framework: This refers to the full range of health, nutrition, early education and social services that provide for the holistic needs of children 0 to 6 and to promote their optimum growth and development. These include center-based programs (e.g. day care service, preschool, kindergartens, and workplace-based services) and home-based programs (e.g. parent education, playgroups, home visitation, and family day care).

The ECCD System Components: The ECCD System includes five components: (1) ECCD Curriculum that focuses on the child's total development, delivery of complementary and integrative services for health care, nutrition, early childhood education, and social protection and the use the child's first language as the medium of instruction; (2) Parent Education and Involvement, Advocacy and Mobilization of Communities to harness and develop parents' strengths as providers of ECCD at home, and active ECCD partners in their communities; (3) Human Resource Development Program which entails establishing the mechanism for the systematic professionalization of ECCD service providers; (4) ECCD Management which focuses on the continuing process of planning, implementation, supervision, financial management, monitoring and evaluation of
ECCD at the local government level guided by the principles of decentralization as stipulated in the Local Government Code of 1991; and (5) Quality Standards and Accreditation to ensure that each component in the ECCD System complies with national quality standards.

ECCD is a shared responsibility: The establishment of the ECCD System is a collective task of various stakeholders to ensure the rights and full development of children 0 to 6 . The roles and relationships of ECCD players at multiple levels are clearly defined i.e. families, communities, nongovernment/private sector, local government units and national government agencies. The "childfriendly wheel" in Figure 2 aptly illustrates ECCD as a collective responsibility, with the child at the hub of the wheel, in keeping with the ecological perspective of the child within the context of his/her family, community and society. This means putting the child at the core of the ECCD agenda while strengthening and/or influencing the environment in which children live and grow up.

National Coordinating Body: The ECCD Act mandated the Council for the Welfare of Children (CWC) to also function as the National ECCD Coordinating Council (NECCDCC) under the Office of the President, but in 2007, by virtue of Executive Order No. 630, it was reverted as an attached agency 


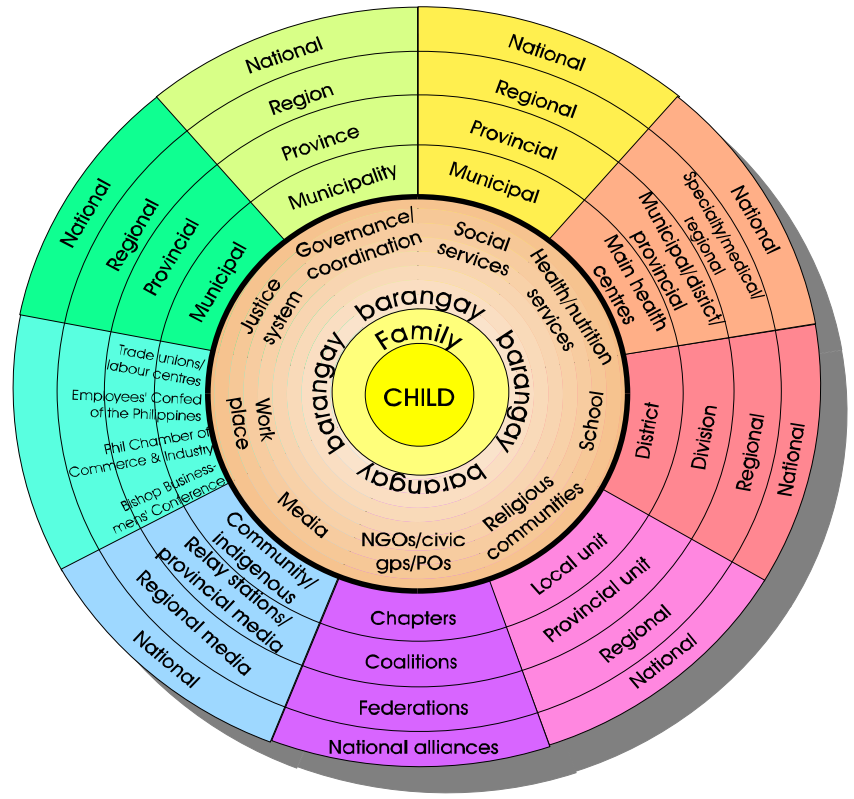

Figure 2. Child 21 Strategic Framework for a child friendly society

to the Department of Social Welfare and Development. The Council is governed by a Council Board that has representation from the key national line agencies, as well as NGOs, ECCD experts and the child sector. The Secretaries of Health, Education, Social Welfare and the Interior and Local Government act as co-chairperson. The CWC Secretariat also serve as the Secretariat of the Council, headed by an Executive Director appointed by the President, with two permanent positions of Deputy Executive Directors appointed by the Council, one of whom is concerned with ECCD and the other with the existing functions of the CWC. An inter-agency Management Committee for ECCD was created to provide program direction by way of recommending policies and standards for the approval of the CWC/NECCDC Board. Section 40 of the Implementing Rules and Regulation of the ECCD Act provides that the Regional Sub-Committee for the Welfare of Children to function as an extension of the NECCDCC.

Local Coordinating Structure: ECCD Coordinating Committees are to be established at the provincial, municipal, city and barangay (village) level. At the provincial and city/municipal levels, the ECCD coordinating committees are supported by an ECCD secretariat; this was not made explicit under the law in the case of the barangay.

\section{Early Childhood Governance in the Philippines}

In early 2009, two policy issuances by the President ${ }^{2}$ changed the landscape of early childhood governance at the national level. The two Executive Orders were issued in January 2009 and June 2009, respectively: (1) E.O. No. 778 "Transforming the Council for the Welfare of Children (CWC) into the Early Childhood Care and Development Council" provided an unequivocal focus on the early years (0 to 6) and abolished the CWC as the mandated National ECCD Coordinating Council, creating a new agency, the Early Childhood Care and Development Council as the lead agency for ECCD $(0$ to 6); and (2) E.O. No. 806 "Affirming the Roles of Early Childhood Care and Development Council and 


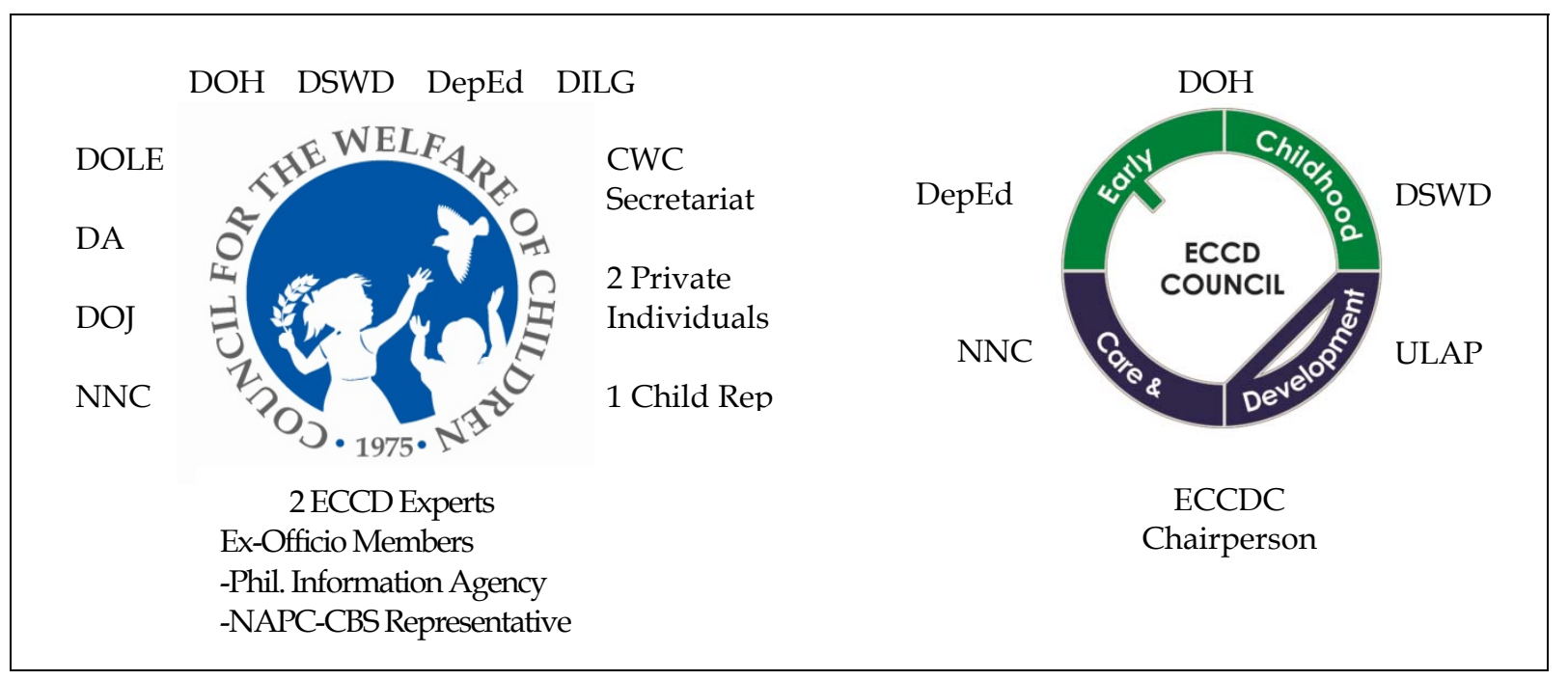

Figure 3. Comparative Structure of CWC and ECCD Council

the Council for the Welfare of Children" which confirmed the existence and roles of two distinct and separate Councils with oversight on children's concerns.

As shown in Figure 3, the CWC/NECCDCC is composed of 17 members that include nine (9) line agencies (multi-sectoral), the CWC Executive Director, two private individuals, one child representative, two ECCD experts and two ex-officio members (Philippine Information Agency and the National Anti-Poverty Commission-Child Basic Sector Representative). The Secretaries of Health, Social Welfare, Education and the Interior and the Local Government rotate as Co-Chairpersons.

Compared to the CWC/NECCDCC, the composition of the newly created ECCD Council is lean. The Governing Board is headed by a Chairperson ${ }^{3}$ appointed by the President (Cabinetrank Secretary) with five members, namely the Department of Health (DOH) ${ }^{4}$, Department of Social Welfare and Development (DSWD) ${ }^{5}$, Department of Education (DepED) ${ }^{6}$, National Nutrition Council $(\mathrm{NNC})^{7}$, and the Union of Local Authorities of the Philippines $^{8}$ (ULAP).
As can be noted, the ECCD Council is composed of national agencies whose mandate covers programs directly benefitting children 0 to 6 . Having a smaller board, it is argued that the ECCD Council is able to champion the needs and rights of children 0 to 6 in a more focused and coherent manner.

At the local levels, the law provides for the organization of ECCD Coordinating Committees to ensure the sustained inter-agency and multi-sectoral collaboration. At the province, the Committee is headed by the Governor. At the municipal/city and barangay levels, the Committees are chaired by the mayor and by the barangay captain, respectively. The greatest challenge remains at the barangay level, the basic political unit and primary planning and implementing arm of government policies, plans and programs. There are about 42,000 barangays in the country.

The coordinating structures at the local level have to operate within the context of the Local Government Code of 1991. Thus they have to work within the ambit of the Local Development Council which is tasked to set the direction of a comprehensive socio-economic development plan to be approved by 
its Sanggunian (local legislative bodies) and coordinating development efforts of the LGUs.

\section{Progress and Challenges in ECCD Governance}

What is the current state of ECCD governance in the country since the passage of the ECCD Act in 2000? This can be viewed by examining the developments within the last ten years. Specifically,

this highlights progress and challenges under the management of the CWC/NECCDC (2000 to 2008) and under the present leadership of the ECCD Council (2009 to the present). The data for this section were drawn from a review of Annual Reports, the ECCD Midterm Review ${ }^{9}$ and the ECCD Policy Review in the Philippines 10 and other related documents.

Under the CWC/NECCDCC: A key achievement of the CWC/NECCDCC as the national coordinating body relates to the establishment of the ECCD System in 79 of the 80 targeted provinces and all 28 targeted highly-urbanized cities. While no targets were set for municipalities and barangays, 638 (42.67\%) municipalities and 4761 (11.33\%) barangays were covered(CWC, 2008). These were accomplished using the ECCD process shown in Figure 4 (CWC, 2006) facilitated by an inter-agency Technical Working

PRE-PLANNING

PLANNING

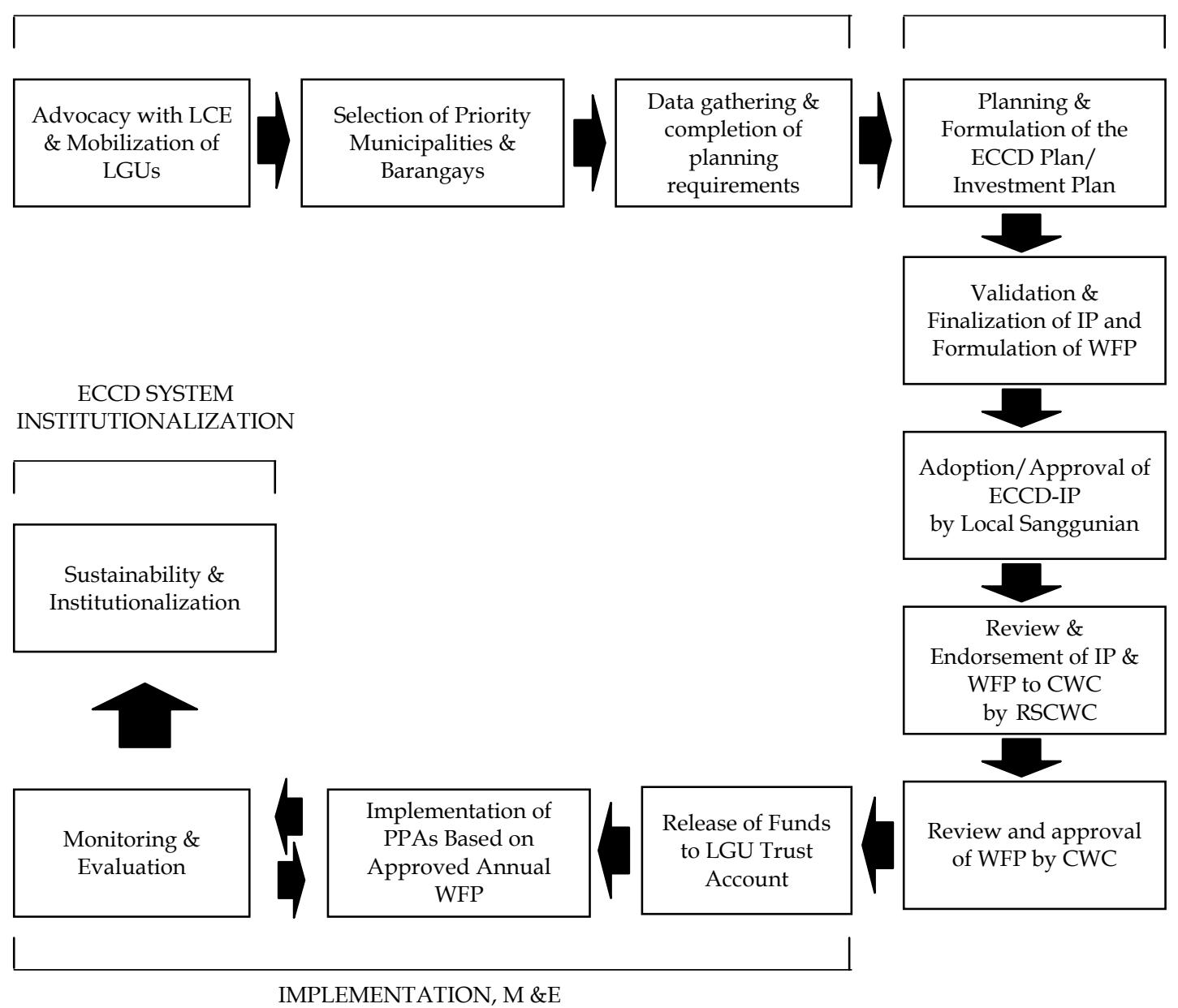

Figure 4. ECCD Process 
Group of the Regional Committee for the Welfare of Children and the Provincial Council for the Welfare of Children/ECCD Coordinating Committee, respectively with technical support from the CWC/NECCDCC Secretariat. While all these can be attributed to the collaborative partnership between and among the coordinating mechanisms at the national, sub-regional and local levels, the involvement of the Local Chief Executives (governors, mayors, barangay chairpersons) and the local ECCD Coordinating Committees at the provincial, municipal, city and barangay levels played a critical role. The Sanggunian (Local Legislative Body) of the province, city, municipality, barangay is a key stakeholder in ECCD; it approves ordinances, passes resolutions and appropriates funds to support ECCD implementation.

The CWC/NECCDCC and the concerned Local Government Units (LGUs i.e. province/city/ municipality) co-funded the ECCD programs/ projects/activities $(\mathrm{P} / \mathrm{P} / \mathrm{A})$ that were implemented. The program boosted and further increased availability of already existing local health and nutrition services for 0 to 6 children. It also rehabilitated and improved day care facilities and health centers. These $\mathrm{P} / \mathrm{P} /$ As also covered parenting and family support, strengthening capacity of service providers (such as day care workers, pre-school teachers, Grade 1 teachers, social workers, doctors, nurses, midwives) and capability of implementing structures, data banking for ECCD and monitoring and evaluation.

The creation of the ECCD Council in early 2009 brought significant changes in affected ECCD operations under the management of the CWC/NECCDCC.

Under the ECCD Council: Through the leadership of Chairperson Teresa Aquino Oreta, the Council defined its two-pronged thrust - strengthening center-based ECCD and modeling/scaling up homebased ECCD to increase access of quality ECCD to children 0 to 6 . In line with these thrusts and in keeping with its function of policy development and standards setting, the Council has made remarkable progress since it started operations in early 2009. As reflected in the ECCD Council Accomplishment Report for January 2009 - June 2010, achievements include: (1) Pilot testing of the 6-week summer ECE program for children entering Grade 1 with no prior ECE experience in the National Capital Region cum tracking the performance of these children in Grade 1. The results compared favorably with other children who underwent regular ECE programs in day care centers and pre-schools; the DepED recognized the importance of the pilot program by implementing its own 6-week summer preschool program nationwide in April to May 2010; (2) State-of-the-Art Review of Day Care Service in the Philippines: A Survey Research ${ }^{11}$, the first-ever comprehensive review of day care service since its inception in 1964 done in partnership with the DSWD and LGUs. (3) HomeBased ECCD Demonstration Project ${ }^{12}$ was conducted to test its viability of the program as a parallel program to center-based ECCD in order to increase access to ECCD services for children 0 to 6; (4) Development of a National Early Learning Framework; (5) Three-year Tracking of the Performance of Children enrolled in DepEd's 6-week Summer Pre-school Program starting SY 2010-2011 to SY 2012-2013 in partnership with DepED; (6) Development of the ECCD Management Information System and National ECCD Resources Database; and (7) Formulation of the ECCD Strategic Plan for 2011-2016.

As cited earlier, the two policy issuances of 2009 resulted in the creation of the ECCD Council as the lead agency for early childhood in the country. This policy change affected the ECCD mechanisms and structures at the sub-regional and local levels that were established under the CWC/NECCDCC. For instance, the 17 regional ECCD Coordinating Committees were abolished. This also had concomitant effects at the local levels.

A major challenge for the ECCD Council relates to 
its stability as an organization. Compared with the CWC/NECCDCC the Council to date has no approved organizational structure; nor its budget included in the General Appropriation Act of the government; it continues to operate using the balance of funds provided under the ECCD Act and nominally supported administratively by the Office of the President. In August 2010, the Office of the
President referred to the Secretaries of national government agencies who are members of CWC for comment and recommendation on the proposed Executive Order transferring the National Early Childhood Care and Development Council (NECCDCC) to the Council for the Welfare of Children (CWC) under the DSWD as its attached agency. Reasons cited for the proposed transfer are

Table 1

Summary of the Gains and Challenges

\begin{tabular}{|c|c|}
\hline Gains & Challenges \\
\hline \multicolumn{2}{|c|}{ Policy Environment } \\
\hline $\begin{array}{l}\text { - A remarkable policy framework - the ECCD Act } \\
\text { of } 2000 \text { is comprehensive, integrative, and holistic } \\
\text { in approach and has integrated funds to support } \\
\text { implementation of the policy } \\
\text { - Positive enabling policy environment with a } \\
\text { number of laws in place related to ECCD } \\
\text { - Resolutions and/or ordinances issued by local } \\
\text { legislative bodies in support of ECCD }\end{array}$ & $\begin{array}{ll}\text { - } & \text { Enforcement still weak } \\
\text { - } & \text { Lack of political commitment } \\
\text { - } & \text { Integration and convergence are concepts not yet } \\
\text { internalized at all levels } \\
\text { - Inadequate financing }\end{array}$ \\
\hline
\end{tabular}

\section{ECCD Governance Structures / Mechanisms}

- Presence of multi-sectoral and inter-agency coordination mechanisms at national and local levels

- Existence of lead agency for ECCD

- Roles for national agencies, local government units, etc. clearly spelled out in the ECCD Act
- Implementing a coherent cross-sectoral coordination a key challenge

- Functionality of local structures

- Organizational stability of the ECCD Council/ issue of "attachment" or "transfer"

- Clarity of the concept of integration and convergence

\section{ECCD in a Devolved/Decentralized Set up}

- Positive efforts of local government units in integrating ECCD in local development plans in keeping with the Local Government Code of 1991

- Sense of ownership of the ECCD program by the LGU

- Greater accountability from the Local Chief Executives (governors, mayors, barangay chairpersons) and the local legislative councils at the provincial, municipal, city, and barangay levels.
- $\quad$ Linkage of local plans

- Financing issue

- Uneven policy implementation, access and quality of ECCD services

- Can lead to fragmentation of resources/service delivery Ownership of LGUs in a devolved set up of national government commitments

- Issue of subsidiarity

- National government oversight and regulations 
two-fold: the creation of two (2) separate entities to attend to the concerns of 0 to 6 years old and that of 7 to below 18 years old does not promote a multisectoral approach in addressing the varied and complex issues confronting the children sector which is contrary to the aims of the UN Convention on the Rights of the Child; and that one of the top priorities of the present administration is the streamlining of attached agencies under the Office of the President. Nevertheless, in August 2010, the Executive Director of the ECCD Council was appointed by President Benigno Simeon Aquino III; a new Chairperson has yet to be appointed.

Given this organizational challege, the ECCD Council under the leadership of Chair Teresa Aquino Oreta, a leader with a vision, passion and commitment for ECCD, has proactively pursued making the ECCD as an integral component of the country's national development agenda.

The passage of the ECCD Act is a significant step towards achieving the ideal mechanism for ECCD in the country. However, as reported in the ECCD MTR (CWC, 2008) and ECCD Policy Review (CWC, 2009) some structures that have been established at the local levels are not fully functional as they should be. Moreover, not all local ECCD coordinating committees were optimized as a mechanism for the integration of services with some members remaining sectorally focused along their mandates. The ECCD MTR also underscored as the overall challenge the effective and efficient delivery of integrated ECCD services to all 0 to 6 Filipino children in a systematic, coordinated, and sustained manner to ensure their rights to survival, development and protection.

In summary, the ECCD Act provides the legal framework for an ideal inter-agency, multi-sectoral structural arrangement aimed at ensuring sustained collaboration at the national and local levels. However, as the foregoing discussion indicates, a good policy does not necessarily translate into its effective execution. On the other hand, the valuable insights and lessons learnt from a decade of implementing the national policy on ECCD provide an excellent starting point to further enhance early childhood policy development and implementation.

A summary of the gains and challenges in governance of early childhood in the country is presented in a Table 1 to show that for every gain there is/are corresponding challenges that need to be addressed. These are interrelated themes that continue to confront ECCD governance since the enactment of the ECCD Act 10 years ago.

The implementation of the ECCD Act has shown some headway. In general, both the ECCD Mid-Term Review and the ECCD Policy Review in the Philippines conclude that the major challenge in implementing the ECCD Act relates to cross-sectoral coordination, that would ensure a comprehensive, integrative and sustainable ECCD services aimed at improving the quality of life of Filipino children 0 to 6 .

\section{Ways Forward}

In the light of the above discussion and cognizant of the issues on limited and inequitable access and low quality ECCD services for children 0 to 6, three action areas are proposed:

ECCD legislative agenda: ${ }^{13}$ For the Philippine government to take cognizance of the age $0-6$ as the foundation cycle of educational development ${ }^{14}$. The various stages of educational development take place sequentially or in cycles and regarded as lifelong learning, ECCD being is the first step in lifelong learning and human development. Adoption of such policy will not only improve the child's overall development at an age when brain development is at its peak, it will also contribute to better achievement in primary school. Consequently, an improvement in the efficiency of the education system is attained. This legislative plan implies some amendments to the ECCD Act of 2000 and other related legal frameworks. This is a priority agenda of the ECCD Council for 
2011 under the $15^{\text {th }}$ Congress.

ECCD policy advocacy agenda: A concomitant policy concern is promoting increased investments available for ECCD, as an instrumental, frontline strategy for achieving the country's poverty reduction goals, MDGs, EFA, etc. This would entail ensuring the ECCD agenda is integrated into the new Philippine Development Plan: 2010-2016 ${ }^{15}$, in sector plans (health, nutrition, early childhood and social welfare/protection) and in local development plans and investment plans of the local government units (provincial, municipal, city, barangay). Along with mainstreaming ECCD in national and local plans, it is imperative that a comprehensive advocacy strategy for ECCD be put in place.

ECCD policy research agenda: Evidence-based knowledge is needed to design solid and effective policies. Policy research need to be pursued that produce information in a form that policymakers can use. This goes with the need for a robust monitoring and evaluation system that will provide timely, clear and updated appropriate information to support evidence-based decision making for policymakers and various stakeholders.

\section{References}

Angara, E. J. (2010). Senate bill 2567: An act recognizing the early years from $0-6$ as the first cycle of educational development (Philippines: 15th Congress). Retrieved March 20, 2011, from http://www.senate.gov.ph/lisdata/103198837!. pdf

Britto, P. R., \& van Ravens, J. (2009, December). Sustainable national policies for ECD. Paper presented during the Regional ECD Policy Review Seminar, Singapore.

Bureau of Child and Youth Welfare (1995). The Child and Youth Welfare Code (Presidential Decree no. 603 as amended). Quezon City, Philippines: Author.

Council for the Welfare of Children [CWC]. (2002).
The early childhood care and development Act (Republic act No. 8980) and The implementing rules and regulations. Quezon City, Philippines: Council for the Welfare of Children.

Council for the Welfare of Children [CWC] \& United Nations Children's Fund [UNICEF]. (2000). Philippine National Strategic framework for plan development for children, 2000-2025: A legacy to the Filipino children of the 21st century. Makati City, Philippines: Author.

CWC. (2005). Philippine plan of action for children 20052010. Quezon City, Philippines: Author.

CWC., \& UNICEF. (2008). Early childhood care and development policy review in the Philippines. Unpublished manuscript.

CWC. (2006). Accomplishment reports 2006. Quezon City, Philippines: Author.

CWC. (2007). Annual reports. Quezon City, Philippines: Author.

CWC. (2008). Annual reports. Quezon City, Philippines: Author.

CWC. (2008). ECCD mid-term review. Unpublished manuscript.

Early Childhood Care and Development Council [ECCDC]. (2009). A state-of-the-art review of day care service in the Philippines: A survey research. Makati City, Philippines: Author.

ECCDC. (2010). Accomplishment report January 2009 June 2010. Makati City, Philippines: Author.

National Economic and Development Authority [NEDA]., \& United Nations Development Programme [UNDP]. (2010). Philippine progress report on the millennium development goals 2010.

National Statistics Office [NSO]. (2000). Census of population and households by single age, CY 20002010. Santa Mesa, Philippines: Author.

National Statistics Office [NSO]. (2008). 2007 census of population and households. Santa Mesa, Philippines: Author.

Nolledo, J. N. (2004). The local government code of 1991 annotated 2004 edition. Mandaluyong City, Philippines: National Bookstore. 
Office of the President (2009). Executive order No. 778 transforming the council for the welfare of children into the early childhood care and development council. Philippines: Author.

Office of the President (2009). Executive order No. 806 affirming the roles of the early childhood care and development council and the council for the welfare of children. Philippines: Author.

Office of the President (2010). Proposed Executive order on the transfer of the national early childhood care and development coordinating council (NECCDC) to the council for the welfare of children (CWC). Philippines: Author.

UNICEF. (2010). Situation analysis of Filipino children and women. Unpublished manuscript.

\section{Notes}

${ }^{1}$ An Act Promulgating a Comprehensive Policy and a National System for Early Childhood Care and Development (ECCD), Providing Funds Therefore and for Other Purposes. The Implementing Rules and Regulations of the ECCD Act was adopted by the CWC/NECCDCC Board only in April 2002.

2 The Administrative Code of 1987 grants the President the continuing authority to reorganize the Executive Branch of Government.

${ }^{3}$ Former Senator Teresa Aquino-Oreta, the principal author of the ECCD Act of 2000 is the first appointed Chairperson of the ECCD Governing Board.

${ }^{4}$ The agency is primarily responsible for mothers and young children under five.

${ }^{5}$ The agency is tasked with the development of programs and standards for day care service for children 3-5 years old and parent effectiveness service.

6 The agency is responsible for preschool through basic education

${ }^{7}$ An attached agency of the $\mathrm{DOH}$

8 The umbrella organization of all the Local Government Units (LGUs) and its elected officials and which functions as the national coordinating body for the various government officials of provincial, city, municipal and barangay levels.

${ }^{9}$ The 2008 ECCD Mid-Term Review was designed to appraise ECCD at its mid-point implementation, the results of which can be used to improve the program processes and policies to fully attain the ECCD goals. It looked at the extent to which the ECCD law was operationalized by reviewing: (1) institutional mechanisms or structures at national and local levels; (2) institutional building/capability building for ECCD coordinators and service providers (day care workers, pre-school teachers, Barangay health workers, and barangay nutrition scholars), and mothers/parents and (3) the LGU responsibilities and how these contributed to the state of implementation of the ECCD Law.

10 This was undertaken as part of the UNESCO-UNICEF Regional ECCD Policy Review covering eight countries to support Asia-Pacific countries in meeting the first goal of EFA. The objectives of the study were (1) to determine the level of to the basic ECCD services and the factors affecting access; (2) to assess the quality of ECCD services; (3) to characterize the nature of integration and convergence of ECCD services; and (4) to assess the mechanisms and structures established for the program. The study was conducted in five provinces where the ECCD were already implemented.

11 The study established the profile of 49,712 day care centers, 49,865 day care workers, and 1646 day care worker supervisors. The results of the study will serve as inputs to policy formulation, crafting of legislative agenda, designing focused strategies, and developing the ECCD's 5-year Master Plan.

12 The project mobilized the frontline health workers at the barangay level who were trained to facilitate parent education sessions and playgroups for children. The project served as springboard for the development of the National Implementation Plan for Home-based ECCD as guide in eventual scaling up.

13 As of October 20, 2010, the proposed bill "An Act Recognizing the Early Years From 0 to 6 Years Old as the First Cycle of Educational Development and for the Purpose Amending Republic Act No. 8980, Strengthening the Early Childhood Care and Development Council" or "The Early Years Act" has been filed both at the Lower House (HB No. 3507) and the Senate (SB No. 2567). If the bill is passed, this will address the organizational challenge faced by the ECCD Council both in terms of its organizational structure and funding, which are critical in the effective and efficient performance of its role as the mandated national ECCD governing body.

${ }^{14}$ A model learning system consisting of five (5) cycles of 
educational development suggested in 2004 by the National Commission of the Philippine Education Committee.

15 The plan is currently being finalized under the leadership of the National Economic Development Authority(NEDA), the Philippines' social and economic development planning and policy coordinating body. 